\title{
Bulletin of the American Mathematical Society
}

This journal is the official organ of the Society. It reports official acts of the Society and the details of its meetings. It contains some of the officially invited addresses presented before the Society, reviews of advanced mathematical books, and a department of research announcements.

The subscription price is $\$ 12.00$ per annual volume of six numbers.

Invited Addresses offered for publication should be sent to MURRAY GerstenHABER, Department of Mathematics, University of Pennsylvania, Philadelphia, Pennsylvania 19104.

Book Reviews should be sent to GIan-Carlo Rota, Mathematics Department, Massachusetts Institute of Technology, Cambridge, Massachusetts 02139.

All Research Announcements should be sent to M. H. ProtTER, Department of Mathematics, University of California, Berkeley, California 94720.

All other communications to the editors should be sent to the Managing Editor, Murray Gerstenhaber, at the above address.

\section{Proceedings of the American Mathematical Society}

This journal is devoted entirely to research in pure and applied mathematics and is devoted principally to the publication of original papers of moderate length. A department called Shorter Notes was established for the purpose of publishing very short papers of an unusually elegant and polished character, for which there is normally no other outlet.

Papers in algebra, number theory, and algebraic geometry should be sent to George B. Seligman, Department of Mathematics, Yale University, New Haven, Connecticut 06520 or JosEPH J. Rorman, Department of Mathematics, University of Illinois, Urbana, Illinois 61801 ; in modern or classical analysis to IRvING GLICKSBERG, Department of Mathematics, University of Washington, Seattle, Washington 98105, W. H. J. Fuchs, White Hall, Cornell University, Ithaca, New York 14850 or to Allen Shields, Department of Mathematics, University of Michigan, Ann Arbor, Michigan 48104; in set-theoretic and general topology to ERNEST A. MichaEL, Department of Mathematics, University of Washington, Seattle, Washington 98105; in algebraic topology and all other geometry to P. EMERY THOMAs, Department of Mathematics, University of California, Berkeley, California 94720; in applied mathematics, differential equations, and related areas of analysis to WoLFGANG WAsow, Mathematics Department, University of Wisconsin, Madison, Wisconsin 53706; in probability, statistics, and related fields to JoshuA CHOver, Mathematics Department, University of Wisconsin, Madison, Wisconsin 53706; in logic, set theory, and related areas to W. W. Boone, Mathematics Department, University of Illinois, Urbana, Illinois 61801 . All other communications should be addressed to the Managing Editor, W. H. J. Fuchs.

\section{Transactions of the American Mathematical Society}

This journal is devoted entirely to research in pure and applied mathematics, and includes in general longer papers than the PROCEEDINGs.

Papers in analysis and applied mathematics should be sent to J. J. KoHn, Department of Mathematics, Princeton University, Princeton, New Jersey 08540; in topology to Steve Armentrout, Department of Mathematics, Pennsylvania State University, University Park, Pennsylvania 16802; in algebra, number theory, and logic to D. A. Buchsbaum, Department of Mathematics, Brandeis University, Waltham, Massachusetts 02154; in geometry and abstract analysis to SHLOMo STERnBERG, Department of Mathematics, Harvard University, Cambridge, Massachusetts 02138; in statistics and probability to H. P. McKeAN, Department of Mathematics, Rockefeller University, New York, New York 10021; in mathematical logic and foundations to Dana Scotr, Department of Mathematics, Stanford University, Stanford, California 94305 . All other communications to the editors should be addressed to the Managing Editor, Dana Scotr.

\section{Memoirs of the American Mathematical Society}

The Memorrs of the American Mathematical Society constitute a series of paperbound research tracts which are of the same general character as the papers published in the Transactions. An issue of the MEMoIrs contains either a single monograph or a group of cognate papers. The Memorrs are printed by the photo-offset process. Information on preparation of camera copy and charges for publication may be obtained by writing to the Editorial Department of the American Mathematical Society. 


\section{Journals Published by the \\ American Mathematical Society}

\section{Soviet Mathematics-Doklady}

This bimonthly is a translation journal containing the entire pure mathematics section of the DokLady AKademi Nauk SSSR, the Reports of the Academy of Sciences of the USSR. The DokLADY for a year contains about 500 articles, each about 4 pages long.

\section{Mathematical Reviews}

This journal is devoted to abstracts and reviews of the current mathematical literature of the world. Two volumes of MATHEMATICAL REVIEWS will be published in 1969, Volume 37, and Volume 38. Each volume will consist of 6 regular issues plus an index issue. In each regular issue the abstracts and reviews are grouped under subject headings. Publication began in 1940.

\section{Notices of the American Mathematical Society}

This journal announces the programs of the meetings of the Society. It carries the abstracts of all contributed papers presented at the meetings of the Society and publishes news items of interest to mathematical scientists.

All communications should be addressed to the Editor, P.O. Box 6248, Providence, Rhode Island 02904. News items and insertions for each issue must be in the hands of the editor on or before the deadline for the abstracts for the papers to be presented in the meetings announced in that issue. These deadlines are published regularly on the back of the title page.

\section{Mathematics of Computation}

A journal devoted to original papers in numerical analysis, the application of numerical methods and high-speed calculator devices, the computation of mathematical tables, the theory of high-speed calculating devices and other aids to computation. In addition it publishes reviews and notes in these and related fields.

Prospective publications should be addressed to the Editor, Professor Eugene Isaacson, Courant Institute of Mathematical Sciences, New York University, 251 Mercer Street, New York, New York 10012. The author may suggest the name of an editor for review of his paper.

\section{New Publications}

This quarterly journal announces new books and journals in all fields of higher mathematics, including a section on both forthcoming and recently published books. The information is acquired from several sources, such as pamphlets and catalogs received from publishers and book dealers from many parts of the world.

\section{Mathematics of the USSR-Izvestija}

This journal is a cover-to-cover translation of IzvestiJa AkadEMIr NAUK SSSR Serija Matematičeskaja published bimonthly by the Academy of Sciences of the USSR. It is a journal of current research in all fields of pure mathematics. Starting with Volume 1, Number 1, January-February 1967, which corresponds to the Russian original Tom 31, Number 1, the translation is prepared by the Plenum Publishing Corporation with the cooperation of the American Mathematical Society, and is published bimonthly by the American Mathematical Society.

\section{Mathematics of the USSR-Sbornik}

This journal is a cover-to-cover translation of MATEMATIČEskił SBoRNik (New Series), published monthly by the Moscow Mathematical Society and the Academy of Sciences of the USSR. It is a journal of current research in all fields of pure mathematics. The translation is published monthly starting with Volume 1, Number 1 , January 1967, which corresponds to the Russian original Tom 72 (114), No. 1. 
Contents-continued from back cover

Paul Ponomarev. On class numbers of positive definite quaternary

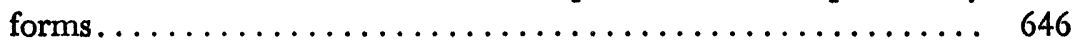

Peter S. Landweber. On the complex bordism and cobordism of infinite complexes. . .................... 650

David W. Henderson and James E. West. Triangulated infinitedimensional manifolds...................... 655 


\section{GONTENTS}

\section{May, 1970}

P. Masani. Quasi-isometric measures and their applications...... 427

Harish-Chandra. Harmonic analysis on semisimple Lie groups. . . 529

François Treves. On local solvability of linear partial differential equations .............................. 552

The Annual Meeting in San Antonio................. 572

The November Meeting in Ann Arbor.................. 583

Steele prizes for expository papers.................. 584

M. Cahen and N. Wallach. Lorentzian symmetric spaces........ 585

John Guckenheimer. Axiom $A+$ no cycles $\Rightarrow \zeta_{f}(\mathrm{t})$ rational....... 592

Edward T. Dean and Paul L. Chambré. On the solutions of the nonlinear eigenvalue problem $L u+\lambda b(x) u=g(x, u) \ldots \ldots \ldots . .595$

Larry Smith. An application of complex bordism to the stable homotopy groups of spheres.................... 601

Robert H. Risch. The solution of the problem of integration in finite terms............................. 605

Steven Orey. Growth rate of Gaussian processes with stationary increments................................... 609

D. H. Van Osdol. Remarks concerning $\operatorname{Ext}^{*}(M,-) \ldots \ldots \ldots .612$

James Keesling. Normality and compactness are equivalent in hyperspaces............................ 618

B. J. Matkowsky. A simple nonlinear dynamic stability problem... 620

H. Rhee. Expression for a function in terms of its spherical means. . 626

P. R. Ahern and D. N. Clark. On star-invariant subspaces..... 629

Melvyn S. Berger. On periodic solutions of nonlinear hyperbolic equations and the calculus of variations............... 633

Seymour Bachmuth, Horace Y. Mochizuki and David Walkup. A nonsolvable group of exponent $5 \ldots \ldots \ldots \ldots \ldots \ldots \ldots \ldots .638$

Phillip A. Martens. Representations of infinite dimensional manifolds and $\infty$-p homology functors................... 641

Continued on inside back cover 